\title{
El historiador y su obra: Futuro pasado, de Reinhart Koselleck ${ }^{1}$
}

\author{
Dieter Langewiesche \\ Universität Tübingen \\ dieter.langewiesche@uni-tuebingen.de
}

Señoras y señores:

Cuando se escucha una conferencia sobre una persona a la que el orador valora especialmente conviene guardar las distancias. Es el caso de esta tarde.

Conocí a Reinhart Koselleck siendo yo estudiante en Heidelberg, a finales de la década de 1960, y, aunque entonces en la distancia del aula, me dejó inusualmente impresionado como joven universitario que yo era. Luego pude encontrarme con él dos veces casi todos los años durante varios días, en los debates del Arbeitskreis für moderne Sozialgeschichte (Grupo de trabajo de historia social moderna), en aquella época un importante foro de discusión interdisciplinar para la historiografía alemana. Allí nos conocimos también personalmente, en largas veladas de discusión.

No he sido alumno de Koselleck, pero su modelo de historia de los conceptos ha influido en mi forma de abordar la historia. Un reseñador británico escribió una vez que Koselleck es mi ídolo doméstico para cuestiones teóricas. Me parece excesivo. Sí es verdad que uno y otro compartimos nuestro aprecio por un teórico de la historia del siglo XVIII, del cual opinábamos que había sabido, ya entonces, casi todo lo que hoy sabemos sobre la perspectiva en el conocimiento y el análisis de la historia. Casi todo. La teoría de Chladenius ${ }^{2}$ sobre el

1. Este texto corresponde a una conferencia pronunciada el 30 de junio de 2015, en la Universidad de Tubinga (Alemania), dentro del ciclo Studium Generale, dedicado a los elementos más destacables de las Humanidades (traducción de Jesús Millán, Universitat de València).

2. Johann Martin Chladenius, Allgemeine Geschichtswissenschaft, Leipzig, Friedrich Lancks Erben, 1752, reeditado con una introducción de Reinhart Koselleck (Viena, Böhlau, 1965). 
punto de vista explica por qué la percepción de un acontecimiento depende de la posición en que se sitúe el observador: status social, religión, amigo o enemigo, vecino o extraño, intelectual o no y muchas cosas más. Hoy añadiríamos otros puntos de vista, sobre todo hombre o mujer. Chladenius era consciente también de la "transformación de la historia al narrarse". Quien narra o cuenta por escrito una historia la transforma, al darle una estructura. La estructura temporal contribuye a ello. Pero Chladenius aún no se dio cuenta de que el tiempo que transcurre, el tiempo entre lo acontecido y la narración de lo acontecido, transforma el suceso: este es trasladado a otros contextos y, de esta forma, queda transformado en su significación histórica. Y este precisamente fue el tema de Reinhart Koselleck toda su vida: el tiempo y la historia, la importancia del tiempo para la comprensión de la historia, para la historiografía. Encontrar este cambio del pasado a través del tiempo en el lenguaje, condensado en un concepto. La obra de su vida fue la historia de los conceptos, algo que antes de él no existía de ese modo. Lógicamente, también él se alzaba sobre los hombros de otros.

Koselleck escribió además otras cosas: su trabajo de habilitación sobre Prusia en la primera mitad del siglo XIX; también una historia de Europa en la misma época. ${ }^{3}$ Los expertos valoran estas obras, pero esos libros no lo han hecho famoso. Fue con sus estudios sobre la historia de los conceptos cuando ganó fama internacional.

\section{La persona: Koselleck, historiador}

La cuestión de la historia y el tiempo atraviesa esta obra sobre el análisis semántico de la historia. Y el libro que hoy nos ocupa expresa este punto de vista también en su título: Vergangene Zukunft. Zur Semantik geschichtlicher Zeiten, Futuro pasado. Sobre la semántica de las épocas históricas. Pero, en primer lugar, digamos algo sobre la persona. Este es el programa de esta serie de conferencias: personalidad, obra, ¿qué es lo que queda en pie?

La persona. En una entrevista sobre su forma de considerar la historia, dijo una vez que él "prefería abordar la historia en su conjunto como profano...

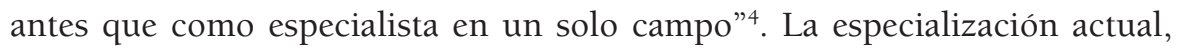

3. Reinhart Koselleck, Preußen zwischen Reform und Revolution. Allgemeines Landrecht, Verwaltung und soziale Bewegung von 1791 bis 1848, Stuttgart, Klett-Cotta, 1967 (con varias reed. posteriores); Louis Bergeron, Francois Furet, Reinhart Koselleck, Das Zeitalter der europäischen Revolution, Frankfurt am Main, Fischer Verlag, 1969 (trad. cast. de F. Pérez, Madrid, Siglo XXI, 1976).

4. "Begriffgeschichte, Sozialgeschichte, begriffene Geschichte. Reinhart Koselleck im Gespräch mit Christof Dipper", Neue politische Literatur (1998-1), pp. 187-205. 
como sucede por ejemplo en historia contemporánea en exclusiva -la gente se habilita incluso en esto-, era una "catástrofe", según su opinión. El modelo de historia de los conceptos de Koselleck está organizado a base de largos periodos temporales. A menudo, desde la antigüedad griega y romana. Con la especialización no podía hacer nada. Y así estaba organizada también su carrera académica. Según creo, en esto pueden reconocerse sus orígenes.

Koselleck se crió en una familia de la Bildungsbürgertum ${ }^{5}$. Esto modeló por completo su forma de vida, incluyendo la científica, e irrumpió una y otra vez en su biografía. La formación intelectual como forma de vida. Así se hizo fotografiar, para un artículo con motivo de su octogésimo cumpleaños, en el Frankfurter Allgemeine Zeitung. Vivir como un burgués ilustrado, según contaba Koselleck, significaba en su familia: "tocar música en casa, leer, leer de nuevo, asistir a conciertos y visitar museos, estar orgulloso de la historia de la familia y escribir cartas. Mi madre escribía casi todos los días de cuatro a cinco cartas. Mi familia es la confluencia de una familia burguesa de origen hugonote, instalada en el mundo académico durante más de siglo y medio, por parte de madre, con la familia de mi padre, que había ascendido socialmente hacía poco". Su madre, como hugonote, había estudiado en francés, naturalmente en Ginebra, no en Francia, y como hija de una familia de la burguesía ilustrada se había formado como concertista de piano. El abuelo materno podía permitirse darle estos estudios, ya que era catedrático de medicina. Posiblemente esto aseguró luego la supervivencia de Koselleck tras la II Guerra Mundial en el cautiverio soviético. Allí lo operó un antiguo médico asistente de su padre, quien se preocupó, además, de que bastante pronto, hacia finales de 1946, fuese liberado de su encierro ${ }^{6}$. La red de contactos de la burguesía ilustrada, decía Koselleck, lo preservó y lo recogió.

Su familia contribuyó a darle unos conocimientos educativos que hicieron posible la amplia formación de Koselleck -lo que hoy, seguramente en tono de censura, se llamaría su curriculum desestructurado, carente de objetivo y despilfarrador de tiempo- y lo dotaron estupendamente para su manera de plantearse la historia. Según contaba, durante los años de su carrera "se consumió de una facultad a otra, haciendo trabajos, asistiendo a cursos y leyendo". Entre sus profesores más importantes citaba a los filósofos Heidegger, Gadamer y Löwith. $\mathrm{Y}$ al jurista Carl Schmitt. Muchos se tomaron esto a mal y su agradecimiento

5. "Burguesía con formación" (académica). Este término designa a los sectores burgueses que se caracterizan por su cualificación universitaria como profesionales, altos funcionarios o expertos con suficiente independencia y prestigio social (N. del t.).

6. Manfred Hettling, Bernd Ulrich, "Formen der Bürgerlichkeit. Ein Gespräch mit Reinhart Koselleck", en Id., ed., Bürgertum nach 1945. Hamburgo, Hamburger Ed., 2005, pp. 40-60. 
a Carl Schmitt en el prólogo de su tesis doctoral le costó no ser designado para su primera plaza como profesor universitario. Koselleck decía de Schmitt que había sido "uno de los estímulos intelectuales más agudos que he encontrado en mi vida"'. Esto era lo que contaba para él, no lo que Schmitt había escrito en la época del nazismo. "Eso, simplemente, me interesa poco. Puesto que para mí estaba muy claro que todos estaban liados con el nazismo. Saldar cuentas morales por ese motivo me quedaba lejos".

Puede verse en ello una forma de guardar silencio, quizás también condicionada en parte por su familia, pues el padre de Koselleck, que había sido un conocido reformador de la pedagogía durante la República de Weimar, primero fue destituido por republicano por los nazis, pero luego, cuando fue readmitido, ingresó en 1936 en la caballería de las SA, a fin de protegerse a sí mismo y a su entorno. Su padre también estaba, por tanto, en ese lío. Igual que el mismo Koselleck, quien en 1941, siendo alumno de Gymnasium, se enroló voluntariamente en el ejército, junto con toda su clase. De esta forma, podían elegir el arma de destino ${ }^{9}$. Liarse como protección: así podría interpretarse lo que contaba Koselleck.

Con todo, en su desinterés por las implicaciones concretas de personas individuales en el nacionalsocialismo puede verse arraigada también su forma de analizar la historia, tal como la ensayó en su tesis doctoral Kritik und Krise. Eine Studie zur Pathogenese der bürgerlichen Welt $/{ }^{10}$ Crítica y crisis. Un estudio sobre la patogénesis del mundo burgués. Entonces, en 1954, toda una llamada de atención; todavía ahora, un libro sugerente, ya que analiza la proclividad de la utopía a transformarse en totalitarismo. Hoy, una vez más de actualidad. En aquella época, una vía para plantearse las raíces del nacionalsocialismo $^{11}$. El libro tuvo un éxito extraordinario. Hasta 1973 aparecieron 12 ediciones. ¡De una tesis!

La inserción social de Koselleck en la burguesía ilustrada creó una red en la que vivía y pensaba. Esto le ayudó en su carrera académica, él no lo pasaba

7. Reinhart Koselleck, Carsten Dutt, Erfahrene Geschichte. Zwei Gespräche. Heidelberg, Universitätsverlag Winter, 2013.

8. Hettling, Ulrich, "Formen der"..., p. 56.

9. Me lo contó después. Solo un alumno de su clase, un amigo suyo, no pudo enrolarse como voluntario, ya que era de confesión católica. Fue reclutado por vía regular, asignado al arma más peligrosa, la infantería, y cayó en el campo de batalla como soldado poco después.

10. Crítica y crisis. Un estudio sobre la patogénesis del mundo burgués. Madrid, Rialp, 1965 trad. de R. de la Vega; nueva ed. de J. A. Pardos, Madrid, Trotta, 2007, trad. de R. de la Vega y J. Pérez de Tudela. La edición original se publicó en Verlag K. Alber, de Freiburg im Breisgau y Múnich, en 1959.

11. Otros recurrieron también a esa vía, incluso algunos que no tenían nada que ocultar en cuanto a su relación con el nacionalsocialismo. 
por alto. Pero sobre todo le proporcionó un amplio horizonte intelectual. Este era, en sus propias palabras, un "requisito básico para construir una historia de los conceptos que pretenda ser satisfactoria: la capacidad de dominar las disciplinas afines, al menos para poder analizar sus influencias". Disciplinas afines eran para él ante todo la filosofía, la teología protestante -como burgués ilustrado no podía considerar el catolicismo-, la literatura, el arte.

Koselleck estaba abierto a estas disciplinas y, por tanto, también tenía algo que aportarles. Hoy en día no identifico a ningún historiador alemán que sea tenido en cuenta y que influya tanto, por encima de los límites de las disciplinas académicas, como Koselleck. Un pequeño indicio: el libro del que nos ocuparemos hoy se encuentra en Tubinga, además de en la biblioteca universitaria, en las bibliotecas de diez departamentos de ocho facultades distintas.

Este interés más allá de las disciplinas concretas se basa en su modalidad de historia de los conceptos. En esta historia, la cuestión no es el transcurso de los acontecimientos, sino lo que condiciona ese transcurso. No como determinación, sino como condiciones de posibilidad para la actuación humana. Koselleck quería encontrar esas condiciones de posibilidad en el lenguaje de los conceptos y en sus cambios. Pero él pensaba también en lo que impregna a la experiencia humana al margen del lenguaje y, de esa forma, impregna su actuación y la historia. Pues la historia consiste siempre en la actuación de la gente. La historia la hacen las personas, a través de su percepción del mundo y de su actuación en ese mundo. Las dos cosas están unidas. Cómo se configura la historia de este modo era lo que Koselleck quería analizar en el lenguaje y, en su última época, cada vez más teniendo en cuenta lo extralingüístico, en especial las imágenes que la gente se hace del mundo. Por eso también los historiadores del arte se ocupan hoy de Koselleck. Pueden encontrar ustedes información al respecto en el libro Reinhart Koselleck und die politische Ikonologie (Reinhart Koselleck y la iconología política) ${ }^{12}$. La exposición de las fotos de Koselleck, que ha exhibido hace poco el Deutsches Literaturarchiv de Marbach, remite precisamente al interés de Koselleck por lo no lingüístico. Pero en su obra como historiador esto ocupa un lugar en el margen, no obstante sus influyentes estudios sobre los monumentos a los caídos de guerra y sus intervenciones públicas en los debates sobre monumentos históricos, el monumento conmemorativo del Holocausto en Berlin y la escultura de Käthe Kollwitz en la Neue Wache de Unter den Linden. La situación existencial de su vida hace sospechar que en esto repercutía la experiencia de su mundo de vida. La experiencia es una categoría fundamental de su obra historiográfica. Era una historia que contaba siempre. También me la contó a mí.

12. Ed. por Hubert Locher y Adriana Markantonatos, Berlin, Deutscher Kunstverlag, 2013. 
Veamos el trasfondo. Como soldado, estuvo en el frente oriental, también en las proximidades de Babi Jar ${ }^{13}$. Había oído hablar, siendo un simple soldado, del asesinato en masa de judíos por parte de una unidad especial alemana, acción en la que fue corresponsable la Wehrmacht. No conoció los detalles, solo la monstruosidad de aquel asesinato masivo. A través de sus familiares, tenía conocimiento del campo de concentración cercano a Weimar, el campo de Buchenwald, y la hermana de su madre, que padecía una enfermedad mental, había sido asesinada en el denominado programa de eutanasia. Todo esto lo sabía, pero no había oído nada durante la guerra del asesinato sistemático de los judíos europeos, según contaba, cuando se produjo la siguiente escena en el campo de prisioneros soviético de Auschwitz. Koselleck estuvo allí, antes de ser enviado a otro campo en Kazajistán, un complejo que eternizó Solzhenitsyn en su Archipiélago Gulag.

"Había allí un vigilante que era de Alta Silesia, que quiso estrellarme un taburete en la cabeza porque yo no pelaba las patatas con suficiente rapidez, pero lo lanzó a la esquina, rompiéndole una pata, y me gritó [al llegar aquí, Koselleck se ponía de pie e imitaba el lenguaje]: "Que tenga que partirte a ti el cráneo, aquí, donde habéis gaseado gente a millones". Ahí, de golpe, me dí cuenta de que no podía ser inventado"14.

El lenguaje y lo no lingüístico, ambos unidos, grabaron de esta forma en su experiencia un suceso que él antes no conocía. De una manera imborrable. Sobre esto reflexionó luego como historiador en importantes trabajos sobre la historia de las experiencias. Una experiencia imbricada en el cuerpo. En ese sentido interpretó enseguida los sueños publicados por Charlotte Beradt bajo el título Das dritte Reich des Traums (El tercer Reich del sueño) ${ }^{15}$. Las historias de esos sueños, decía Koselleck, "testimonian -en cuanto textos de ficción- el terror", pero a la vez son "parte integrante del terror": terror soñado en el cuerpo. Solo aprehensibles por el historiador en la narración de los sueños, pero en el lenguaje -y a través de él- experimentables como acto de terror del cuerpo.

\section{Tiempo, experiencias y expectativas}

Paso de esta forma a la segunda parte: la obra, es decir, nuestro libro. Si ustedes no se han ocupado de Koselleck, les recomiendo como una breve introducción

13. Población de Ucrania, donde se produjo un conocido episodio del genocidio judío tras ser ocupada por la Wehrmacht, en septiembre de 1941 (N. del t.).

14. Koselleck, Dutt, Erfahrene Geschichte..., p. 22.

15. Charlotte Beradt, Das Dritte Reich des Traums, Múnich, Nymphenburger Verlagshandlung, 1966, y Frankfurt am Main, Suhrkamp Verlag, 1981 y 1994 (con un epílogo de Koselleck). Ha sido traducido al francés (París, Payot et Rivages, 2002), italiano (Turín, Einaudi, 1991) e inglés (Chicago, Quadrangle, 1968). 
Erfahrene Geschichte (Historia experimentada), un pequeño librito con dos entrevistas.

Koselleck fue un hombre de textos cortos, no de libros. Es cierto que escribió tres libros, pero no lo hicieron famoso. Su fama fue y es en la actualidad obra de sus ensayos, que él mismo recogió en tres libros: Vergangene Zukunft (Futuro pasado, 1979, $9^{\mathrm{a}}$ ed. en 1988, traducido a varios idiomas) ${ }^{16}$, Zeitschichten (Los estratos del tiempo) ${ }^{17}$ y Begriffgeschichten (Historias de conceptos, en 2006, el año de su muerte $)^{18}$. Por ese motivo no pudo acabar la introducción, en la que quería hacer un balance del tipo de historia que practicaba. El último tomo de Vom Sinn und Unsinn der Geschichte (Del sentido y sinsentido de la historia $)^{19}$ fue editado de manera póstuma en 2010. No sé si ese había sido el deseo de Koselleck. Lo cierto es que él no entregaba un texto a la imprenta con facilidad. Nada le resultaba tan difícil como escribir y, hasta que se imprimían, todos sus textos, a menudo surgidos a partir de conferencias, se modificaban constantemente $e^{20}$. Y dejó sin publicar algunas de sus conferencias. Lo que dejó sin publicar lo tenemos ahora en forma de libro.

El monstruo rojo que ven en la pantalla, nueve gruesos volúmenes, más de 9.000 páginas de formato grande, impresas a doble columna, por tanto, una enormidad de texto, no fue escrito por él mismo, sino que lo editó conjuntamente con Werner Conze: Geschichtliche Grundbegriffe. Historisches Lexikon zur politisch-sozialen Sprache in Deutschland (Conceptos fundamentales de la historia. Léxico histórico del lenguaje sociopolítico en Alemania) ${ }^{21}$. Koselleck

16. Vergangene Zukunft. Zur Semantik geschichtlicher Zeiten, Frankfurt am Main y Berlin, Surhkamp Verlag. (Trad. cast., Futuro pasado. Para una semántica de los tiempos históricos, Barcelona, Paidós, 1993. N. del t.).

17. Zeitschichten. Studien zur Historik. Frankfurt am Main, Suhrkamp Verlag, 2000 (trad. cast. de D. Innerarity, Los estratos del tiempo. Estudios sobre la historia, Barcelona, Paidós, 2001. N. del t.).

18. Begriffgeschichten. Studien zur Semantik und Pragmatik der politischen und sozialen Sprache. Frankfurt am Main, Suhrkamp Verlag, 2006. (Trad. cast.de Luis Fernández, Historias de conceptos. Estudios sobre semántica y pragmática del lenguaje politico y social. Madrid, Trotta, 2012. N. del t.).

19. Vom Sinn und Unsinn der Geschichte. Aufsätze und Vorträge aus vier Jahrzehnten. Berlin, Suhrkamp Verlag, 2010.

20. Una de sus antiguas colaboradoras me contó hace poco, cuando yo le hablaba de mi conferencia de hoy, que ellas preparaban los trabajos impresos de Koselleck a partir de ir pegando muchas, inacabables inserciones que él escribía en papeletas, siempre a mano, y no mediante un ordenador personal, sino todo a mano. Y siempre tenían miedo de colocar las inserciones en un lugar en que no correspondía. No hay que excluir que sucediera algo así, pues muchos pasajes se leen de manera críptica. Pero no se disuadan por ello, vale la pena. Y en el caso de un personaje genial, y él lo era, inserciones en lugares erróneos pueden ser también muy sugerentes.

21. Stuttgart, Klett-Cotta, 1990-1997. 
esbozó la concepción de este léxico, pero en principio había sido previsto para él, como un puesto en espera de su primera plaza en la universidad. No obstante, luego el proyecto creció y creció y muchos artículos tienen la extensión de un libro. Koselleck, con un trabajo paciente y devorador del tiempo, se preocupó de que esta gran obra pudiera completarse y ser publicada. Él mismo escribió algunos artículos; en muchos más incorporó textos parciales de reflexión teórica, ya que los autores no habían entendido qué era lo que él esperaba recibir de ellos.

Este léxico -un gran éxito científico, a escala internacional- parte del supuesto de que en el periodo en torno a 1800 se produjo una transformación fundamental del lenguaje. En una ocasión Koselleck habló, de forma provisional, de un Sattelzeit (periodo "a caballo" o de transición), a caballo entre la premodernidad y la modernidad, un término que ha ganado independencia lógica, sin que él pudiera ya volver a retenerlo. ¿Qué sucedió en esa época, hacia 1800, en términos generales? A eso se refiere la mayoría de los ensayos del libro "Futuro pasado" Lo ilustra bien su breve estudio Historia magistra vitae. Über die Auflösung des Topos im Horizont neuzeitlich bewegter Geschichte (Historia magistra vitae. Sobre la extinción de este principio en el horizonte de la historia que transcurre en la época moderna). Un texto fundamental, que despertó una gran atención y que continúa suscitándola.

La fórmula de la historia como maestra de la vida se acuñó en el mundo antiguo y fue asumida en la historiografía cristiana. Esto es algo característico de la historia conceptual de Koselleck y su léxico está organizado en consecuencia. Se estudian las raíces históricas de un concepto, en este caso de un lema arraigado, para, a continuación, indagar en el cambio experimentado en cuanto a su significado en el periodo en torno a 1800. El núcleo central de este lema "historia magistra vitae" siguió siendo, en todas sus reformulaciones hasta el siglo XVIII, que la historia se repite y, por eso, "el hecho de que la experiencia histórica se pueda enseñar es un aspecto de la misma experiencia".

En el siglo XVIII la palabra historia fue siendo desplazada progresivamente en el lenguaje político alemán por el término Geschichte ${ }^{22}$. Koselleck lo entiende a partir, sobre todo, de textos del debate intelectual y detecta dos transformaciones básicas de significado:

1. Geschichte se transforma en un singular de carácter colectivo. Así lo denominó Koselleck. Singular colectivo, ¿qué significa eso? Geschichte ya no es vista

22. Este sustantivo alemán se incluye en el campo semántico del verbo geschehen (acontecer, suceder), a diferencia del significado griego de historia, que remite al esfuerzo de investigar para conocer (nota del traductor). 
como una colección de historias de las que uno puede aprender de cara al futuro. Una cita representativa de la noción antigua, tomada de un léxico de 1748: "las historias son [Geschichte en plural, es decir, la historia se compone de historias, D. L.] un espejo de la virtud y del vicio, en el que se puede aprender por medio de la experiencia ajena lo que se debe hacer o permitir. Las historias son un monumento de los hechos perversos al igual que de los dignos de alabanza"23. Esa fe en aprender de la historia desaparece ahora, para captar el cambio de significado. Y los cambios revolucionarios de fines del siglo XVIII otorgaron una experiencia, vivida por uno mismo, a esta ruptura en la forma de entender la historia. Ya no se trataba de una discusión más entre académicos, sino de historia experimentada por uno mismo. Alexis de Tocqueville, el gran definidor francés de aquella época, formuló una consecuencia en su obra sobre la democracia en América: "Desde que el pretérito ha cesado de arrojar su luz sobre el futuro, la inteligencia humana anda extraviada en la oscuridad".

Al no entenderse ya la historia como una colección de historias -todas equivalentes, pues todas ellas enseñan lo que uno debe hacer o no-, al abandonarse esta perspectiva, la historia se hace temporal, dice Koselleck. La historia -ya no el plural historias, sino un singular colectivo-, la historia crea su propio tiempo, con sus propias cesuras, ya no las de la mera cronología. Historia se hace singular, se convierte en algo único. Esto nos lleva a una segunda transformación básica, que Koselleck comprueba en el lenguaje conceptual hacia 1800:

2. La historia se experimenta como algo que se puede hacer. La historia se abre al futuro y se interpreta a partir del futuro, que los hombres planean y quieren implantar. Immanuel Kant hizo reflexiones fundamentales acerca del carácter factible de la historia como progreso. Para él, la historia se convierte en un conocimiento reflexivo. La historia ya no narra historias instructivas, sino que documenta qué es lo que subrayan las experiencias vinculadas con una determinada fase histórica y qué la separa de otras épocas. La historia se transforma en un campo de experiencias, pero únicamente cuando se le plantean preguntas a ese campo que uno obtiene de su propia experiencia y de sus expectativas de futuro. Koselleck pone en relación mutua experiencia y expectativa. Lo expuso en un artículo que, probablemente, se cita con más frecuencia que cualquier otro de los suyos y las dos ideas que constituyen su título se han transformado en algo autónomo a partir de esas citas: campo de experiencias y horizonte de expectativas. Veamos este trabajo con más detalle. No es un texto

23. Allgemeines Lexikon der Künste und Wissenschaften, Königsberg y Leipzig, Zeisen und Hartung, $2^{a}$ ed., 1748, p. 386. 
sencillo, como todo lo de Koselleck, pues el autor no narra acontecimientos, sino que indaga sus huellas en el lenguaje de los conceptos históricos.

"Que la historia universal debe volver a escribirse de cuando en cuando, sobre eso no queda duda alguna en nuestros días": así resumía Goethe el cambio en la noción de la historia en torno a 1800. Reescribirla no en función de nuevas fuentes, sino en virtud de nuevas experiencias, que transforman nuestra mirada hacia la historia. Esta valoración se une entre quienes vivían hacia 1800 con la experiencia de que el tiempo histórico se estaba acelerando. La aceleración es una experiencia decisiva que conduce a la idea de la era contemporánea (Neuzeit). Sobre esto Koselleck escribió siempre. A partir de esa experiencia de la aceleración, definió la idea de progreso, que en aquella época se convirtió en una noción central. La historia puede hacerse, cuando el individuo configura el progreso. De esta forma surgen los conceptos relacionados con movimientos, que inventó el siglo XIX y nos transmitió a nosotros. Conceptos relacionados con movimientos que se dirigen a crear el futuro de acuerdo con las propias nociones, surgidas de la experiencia histórica, pero en el marco de un horizonte de expectativas que separa claramente la historia y el futuro. Los conceptos más influyentes fueron liberalismo y democratismo, conservadurismo, socialismo, comunismo y marxismo: todos los conceptos terminados en -ismo. Son ideas del progreso y de movimientos para configurar el futuro.

Kant mostró la manera de actuar de estos conceptos tomando como base el de republicanismo. Una invención léxica suya. No la república, que es un concepto antiguo, que desde la antigüedad puede tener contenidos distintos, hasta el término antidemocrático republicanos, en la actualidad. Se trata de un giro total del significado, desde la idea progresista de república, durante la Revolución francesa, hasta las ideas políticas y sociales de los republicanos de nuestros días. El republicanismo, ese concepto creado por Kant, se dirige hacia un programa de futuro, que va detrás de su noción de una historia a priori, es decir, la historia como progreso hacia un mayor grado de humanidad. Y ese modelo de progreso, que se habría encomendado a los seres humanos, se transforma en un programa de acción: el republicanismo. Así define Kant su horizonte de expectativas como un programa para hacer historia.

La historia ahora se concibe como algo que se puede hacer y por eso cambia cada vez más deprisa: la aceleración como experiencia colectiva. Pueden verlo ustedes constantemente en las fuentes de la época en torno a 1800. "El tiempo se escapa, los más inteligentes lo saben hace mucho. El mundo ha experimentado grandes transformaciones de modo tranquilo y estrindente, con el paso suave de los días y con los vendavales y los volcanes de la tierra. Sucederán cosas 
monstruosas. Las mayores cosas serán transformadas". Lo decía en 1808 Ernst Moritz Arndt, un ejemplo de cómo la experiencia de la aceleración también cambia la idea de la historia: el tiempo se escapa. Los conceptos acabados en -ismo recogen esta experiencia, se convierten en conceptos de lucha política, de lucha por el porvenir. En esos conceptos se esboza el futuro y Koselleck está convencido de que mediante el análisis de estos conceptos, basándose sistemáticamente en las fuentes y en cómo se empleaban, puede descifrarse las disposiciones para la acción de la gente, ya que analizamos su horizonte de experiencias. Lo analizamos en el lenguaje de esa gente.

Los conceptos se extraen del lenguaje de las fuentes, este es el verdadero asunto de la historia como ciencia. Koselleck lo convierte en una tarea teóricamente ambiciosa, ya que define como misión central de la historia la elaboración de los conceptos de esas fuentes para obtener categorías de conocimiento científico. Por eso concibe su historia de los conceptos como una vía hacia una "teoría científica de la historia", una Historik, como se la denominaba en el siglo XIX.

Koselleck no escribió esa Historik, pero es lícito entender su obra, tal como se halla reunida en estos libros de ensayos, como el esbozo de esa teoría. Y su artículo sobre el campo de experiencias y el horizonte de expectativas asume en ese sentido una posición central. "No hay expectativa sin experiencia, no hay experiencia sin expectativa", así lo formula Koselleck en ese trabajo. Experiencia y expectativa "constituyen la historia y, a la vez, su conocimiento". Historia (Geschichte) es ahora una palabra para lo que sucede (Geschehen) y, al mismo tiempo, una idea de la reflexión sobre lo que sucede.

Koselleck define así la experiencia: "Experiencia es el pretérito presente, los acontecimientos del cual se han incorporado y pueden recordarse". Consiste en la elaboración racional de la historia, pero también en formas de conducta inconscientes: ambos elementos se funden en la experiencia. La experiencia está vinculada al individuo, cada cual tiene la suya propia, pero al mismo tiempo es colectiva, porque es típica de una época y está compartida por mucha gente. No por todos. Por eso la experiencia es siempre algo controvertido. Sin embargo, existe un espacio colectivo de experiencia. Si los acontecimientos lo destruyen, por ejemplo, por medio de una revolución o por un acontecimiento como el Holocausto, entonces también estalla el horizonte de expectativas que existía hasta ese momento o, por lo menos, queda profundamente cuestionado. El Holocausto -así lo propondría una aplicación de la teoría de la historia de Koselleck-, el Holocausto no pudo ser algo esperado por los judíos y, en consecuencia, no pudieron prepararse para defenderse de él, ya que no guardaba correspondencia con ninguna experiencia histórica. Pero uno de los grandes his- 
toriadores judíos del siglo XX, Yerushalmi, escribió por ese motivo que "nada [...] en la experiencia histórica de los judíos en su relación con los poderes dominantes [habría] podido preparar a los judíos europeos para la suerte que les aguardaba" ${ }^{24}$. Lógicamente, esto no debe impedir que tracemos líneas evolutivas, de las cuales creemos que hay que hacer derivar el Holocausto, pero debemos saber que, al trazarlas, estamos esbozando imputaciones de causas evolutivas que están más allá de la experiencia histórica de la gente que, en aquella época, se acercaba a aquel acontecimiento. La teoría de la historia de Koselleck nos permite, a partir del carácter impredecible del hecho del Holocausto, descifrar teóricamente para qué cosas nos puede preparar la historia, la experiencia de la historia, y para cuáles no. Cuando el futuro hace estallar tanto el campo de experiencia histórica como el horizonte actual de expectativas, entonces la historia es ciega con respecto al futuro. Por tanto, la teoría de la historia de Koselleck, orientada hacia la historia de los conceptos, permite entender también cuáles son los ángulos ciegos en toda experiencia histórica, nuestros propios espacios ciegos y los de quienes nos precedieron.

También existen, explica Koselleck en este ensayo, puros conceptos de expectativa, a los cuales no se puede agregar ninguna base empírica. La Sociedad de Naciones tras la I Guerra Mundial fue un concepto de este tipo. Existía históricamente el concepto de sociedad y estaba cargado de contenido empírico, pero la Sociedad de Naciones esbozaba algo que iba más allá de esta experiencia histórica. Se había recogido un concepto antiguo, pero se había vinculado a una expectativa totalmente nueva, abierta hacia el futuro. Es lo que sucede hoy con la Unión Europea. Las ciencias que se ocupan de esto envuelven lo novedoso con conceptos en los que introducen antiguas experiencias históricas, pero que ya no son capaces de caracterizar lo que se desarrolla en su interior. Porque, en efecto, no hay ningún modelo histórico para la Unión Europea. La falta de seguridad en el lenguaje, argumentaría Koselleck si se hubiese ocupado de esto, la inseguridad conceptual, expresan que en este caso ha estallado un campo histórico de experiencias.

Dejo aquí este tema para poder presentarles un ensayo del libro de Koselleck, Zeitschichten (Estratos del tiempo): "Erfahrungswandel und Methodenwechsel. Eine historisch-anthropologische Skizze" (Transformación de la experiencia y cambio de método. Un esbozo histórico-antropológico). Un ensayo excepcional, de una gran ambición. Pues trata del intento de incorporar dentro de su historia de los conceptos, que estudia las transformaciones, algo que tam-

24. Yosef Hayim Yerushalmi, Diener von Königen und nicht Diener von Dienern'. Einige Aspekte der politischen Geschichte der Juden, Múnich, Karl F. von Siemens-Stiftung, 1995, p. 47. 
bién es una constante de tipo antropológico. Investiga aquí lo que en el conocimiento histórico se prolonga como constante, a través de procesos de transformación y de ruptura. En otras disciplinas es habitual investigar las constantes antropológicas, como sucede en filosofía o en una parte de la etnología. No es normal en la disciplina de la historia. Esta se dedica por completo a investigar la conducta de la gente en determinadas situaciones. Es cierto, la disciplina histórica trata de encontrar modelos colectivos de esa acción, condicionantes sociales, estructuras dentro de las cuales se despliega esa acción y que delimitan las opciones de actuación, estructuras, también, con las que se narra todo esto. En relación con este tema pudieron escuchar ustedes lo que se decía acerca de Hayden White hace dos semanas. Es un caso especial, el de las formas de narración, aunque White pensaba que tomaba en cuenta todo el objeto del historiador. Se equivocaba. Precisamente, porque la historia se ocupa de las estructuras, no se ocupa solo de las que son singulares, sino de las que son típicas de una época, las que se vinculan a un periodo. Esto quiere decir que la historia no tiene nada fácil hacer algo positivo con las imágenes globales de tipo antropológico, que abarcan periodos muy largos. Siempre existirán esas imágenes globales y encuentran mucho interés por parte del público. Es lo que se llama "big history". Casi siempre, en la línea de las ciencias naturales. Es el caso del hombre en el marco de la evolución biológica. Hace un siglo estas cosas eran bestsellers. $\mathrm{O}$, en la actualidad, los intentos de muchos expertos en neurociencias de entender al hombre exclusivamente a partir del cerebro y no a partir de sus actuaciones sociales.

Existe esa posibilidad y, sin duda, es explicativa, pero dentro de la disciplina histórica carece de efecto. No abordaré este problema. Pero ustedes. deberían tenerlo en cuenta, a fin de entender que no es obvio que sea precisamente un historiador de los conceptos, que estudia los cambios, quien ha escrito un ensayo histórico-antropológico.

En este artículo plantea cuestiones difíciles. Me concentraré en la propuesta de Koselleck, según la cual lo que los historiadores suelen hacer podría adscribirse a tres constantes antropológicas. El autor se plantea de qué forma se pueden vincular "las estructuras temporales de la experiencia histórica" con "tres formas de narrarlas". Por tanto, lo que también se plantea Hayden White. Pero la respuesta de Koselleck es muy distinta: solo hay tres formas de escribir la historia, de pensar la historia, desde la Antigüedad hasta nuestros días, con total independencia de qué disciplina sea la que se ocupe de reflexionar sobre la historia. De la historia no se ocupan solo los historiadores. Pero, al margen de quién lo haga, solo hay tres formas de narrar la historia: registrar por escrito (aufschreiben), continuar la escritura (fortschreiben), reescribir (umschreiben). No hay otras, dice Koselleck, pero esto ya es mucho. Veámoslo con más detalle. 
1. Registrar por escrito. Es lo primario. Se registra lo que uno mismo ve o ha oído. Por eso Chladenius diferencia solo entre la narración histórica de los testigos coetáneos y la historia antigua. Para él es historia antigua todo lo que los coetáneos no pueden referir. Por otro lado, tiempo después argumentó de forma similar Maurice Halbwachs. Chladenius ya lo había observado en el siglo XVIII. Cuando el testigo coetáneo registra algo por escrito, eso es un acto innovador. Al mismo tiempo, es un acto de conocimiento, si se pregunta qué es único, que es nuevo, dentro de lo que ha vivido. La cuestión es diferenciar entre acontecimientos singulares y fundamentos a largo plazo para esos acontecimientos. Y eso precisamente, dice Koselleck, sería "una constante antropológica del método" consistente en formarse una noción racional de la historia.

En el registro por escrito la cuestión es el informe auténtico del acontecimiento y, al mismo tiempo, situarlo en grandes ámbitos históricos. Si nos preguntamos qué es lo único de un hecho histórico, entonces estamos buscando las estructuras repetitivas de la historia. A fin de explicarla, los hombres han puesto en marcha instancias, en todas las épocas, que deben ayudar a explicar la persistencia en el cambio: los dioses, por ejemplo, el Dios cristiano o cualquier otro, o grandes nociones, como la nación o las condiciones productivas, el capitalismo, el comunismo. Todos ellos son fundamentos en última instancia. Koselleck quiere hacerlos cognoscibles por la vía de la historia de los conceptos.

2. Continuar la escritura. Es el objeto normal del historiador normal. Por tanto, de la gran mayoría de ellos. No habría que subestimarlo, aconseja Koselleck, pues en ello también existe una mayor experiencia que puede alcanzarse. Esto es posible a través de enfoques teóricos nuevos o modificados metodológicamente. Sucede, por ejemplo, cuando en la disciplina de la historia se aceptan cuestiones y métodos tomados de la etnología o de otras ciencias. Un punto de vista nuevo, para decirlo con palabras de Chladenius.

3. Reescribir. Es el objeto de investigación más incómodo para el historiador. Lo digo de manera defensiva -objeto de investigación-, porque como norma general los historiadores por sí mismos no son quienes reescriben la historia. Mucha gente cree que son ellos quienes lo hacen. Pero se trata de una ilusión. Como norma general, solo llevan a cabo en términos científicos lo que ya se ha consumado en la sociedad. Pues reescribir la historia no es un acto de voluntad individual, sino que presupone una ruptura de la experiencia histórica. La historia tiene que tener una ruptura y, de esa forma, crear nuevas experiencias. Solo entonces comienza 
la reescritura de la historia. Es lo que sucede, pongamos por caso, con el Holocausto.

No se trata, pues, de uno de los muchos giros que constantemente se proclaman hoy en la ciencia, en lo que habría que considerar más bien como estrategias de mercado. De lo que se trata, en realidad, es de rupturas en la experiencia. Ellas son las que imponen la reescritura de la historia. Pues no solo el presente aparece bajo una luz nueva, que no se hace derivar del pasado, sino que la ruptura de la experiencia permite a la vez una visión nueva de la historia. Un nuevo punto de vista, para decirlo con Chladenius, pero un punto de vista a partir del cual el pasado se nos abre en una visión nueva. No se trata de un simple complemento de otros puntos de vista, sino de un punto de vista nuevo, que relativiza todos los demás. No cambian los hechos del pasado, esto no sucede; más bien se incluyen en envoltorios transformados, en contextos transformados, y de este modo adquieren significados nuevos. Significados que, originariamente, no se hallaban inscritos en esos hechos. Es en este sentido como se transforma la historia. A este proceso contribuyen los tres géneros de historiografía: registrar, continuar y reescribir. Y precisamente, dice Koselleck, esto es una constante antropológica: "En esto se apoya el aspecto mínimo que tienen en común todas las vías de investigación histórica, el que nos permite hablar de la unidad de la historia, por más diferencias que se destaquen, se experimenten y se pongan de manifiesto de forma separada".

\section{Conclusión: literatura e historia}

¿Qué sigue siendo válido? Probablemente Koselleck, lo decía ya al comienzo, forme parte de los historiadores con mayor proyección en otras disciplinas a escala internacional. Precisamente porque estudia las bases de la experiencia histórica y las rastrea principalmente en el lenguaje. Esto facilita su conexión con otros campos.

Lógicamente, también tiene críticas. Entre ellas hay muchas que son mezquinas. Es algo que resulta aburrido y no lo trataré. Entre las objeciones más serias está que Koselleck reclama, sin duda, la necesidad de poner de relieve las disposiciones existentes para la actuación humana, pero él investigó una historia totalmente alejada de la acción. De ahí resulta una historia sin individuos que actúen. Sus personajes escriben y hablan, pero no actúan. Es verdad. El tipo de historia que hacía no se dirige a proporcionar una explicación directa de los acontecimientos históricos en situaciones concretas. Esto lo han emprendido otros, incluso alumnos suyos, y han vinculado los análisis semánticos con el análisis de la actuación. Esto elimina un ángulo ciego en la obra de Koselleck. 
Sin duda, todo tiene sus costes y eso también sucede en este caso. La cuestión de las grandes líneas evolutivas y las constantes antropológicas se pierde en estos análisis de problemas concretos ${ }^{25}$.

También se le ha criticado el hecho de que él escriba sobre la semántica de la historia, pero no discuta con los planteamientos de quienes entienden la historia como una forma de literatura. Esto no es verdad. Quizás en este terreno fue demasiado retraído, pero se pronunció con claridad al respecto, entre otras cosas, cuando se distanció decididamente de Hayden White, sobre cuya Metahistoira se discutió aquí hace dos semanas. Para su libro Auch Klio dichtet (También Clío hace literatura) escribió un prólogo ${ }^{26}$. Koselleck consideraba como el problema principal de Hayden White su incapacidad para tomarse en serio lo que es constitutivo de la disciplina histórica, en concreto, el "poder de veto de las fuentes". Una fórmula famosa de Koselleck: el poder de veto de las fuentes. ¿Qué quería decir con eso? Las fuentes -decía Koselleck en contra de todos los que, en el campo de los historiadores, desprecian la teoría- no se expresan por sí mismas. Las fuentes son bobaliconas. Solo llegan a ser elocuentes cuando se les hace preguntas. Lo importante son las preguntas. Pero la respuesta tiene que poder hacer frente a las fuentes. Los historiadores pueden preguntarlo todo, pero frente a sus respuestas las fuentes poseen un derecho de veto. En palabras de Koselleck: "El historiador puede poner cosas en relación. El historiador juzga según premisas que no están contenidas en las diversas fuentes. La verdad histórica, por tanto, es un nuevo ensamblaje [Neuzusammenfügung] de "hechos" y, en consecuencia, un producto de ficción"27. Y, sin embargo, la historia es algo diferente de la literatura. Koselleck explicó en qué consiste esta diferencia ante la Academia Alemana de Lengua y Literatura (Deutsche Akademie für Sprache und Dichtung). En aquella ocasión reflexionó sobre en qué se diferencia el objeto de los escritores y poetas, que le habían

25. De los problemas en la teoría de la historia de Koselleck los mayores son, en mi opinión, la abstracción y la generalización. Los riesgos que se derivan de ello surgen cuando el mismo autor argumenta de manera concreta y con respecto a un caso. Un ejemplo de bulto: en una de las entrevistas que he destacado en la diapositiva se plantea la percepción del terror en la actualidad. Koselleck argumentó: no hay nada nuevo. Solo ha cambiado el objeto del terror. Por decirlo con sus palabras: "En la monarquía se asesina a los príncipes; en la época de la democracia, a la población misma". (Reinhart Koselleck im Gespräch mit Renate Solbach, in: Iablis. Jahrbuch für europäische Prozesse 2, 2003. http://www.iablis.de/iablis_t/2003/koselleck.html).

26. Hayden White, Auch Klio Dichtet oder die Fiktion des Faktischen, Studien zur Tropologie des historischen Diskurses. Stuttgart, Klett-Cotta, 1986, trad. de Brigitte Brigmann-Siepmann.

27. Reinhart Koselleck, entrevista con Hasso Spode en Neue Zürcher Zeitung (en línea), 3 , 1995, 60-63. 
otorgado un premio, con respecto al del historiador. Resumo mucho su postura: la historia está organizada, si quiere ser ciencia -al igual que cualquier otra ciencia-, para quedar superada. La literatura no ${ }^{28}$.

Koselleck no escribió una teoría de la historia, como siempre se le reclamó. Koselleck no era un autor sistemático; fue un autor de grandes sugerencias y para eso lo más adecuado es el pequeño formato del artículo. Con todo, en esos artículos hay un vacío: el tiempo. El pensamiento de Koselleck giraba en torno a dos ideas: ¿qué es la historia? -y en esto fue innovador como ningún otro, me parece- y la historia que trata del tiempo. En este otro sentido no culminó su trabajo. Siempre escribió sobre el tiempo. Quedó pendiente de escribirnos un artículo sobre el tiempo. Pero este es un campo muy amplio ${ }^{29}$. No lo recorreré, para quedarme esta tarde dentro del límite establecido de tiempo.

Espero haberles mostrado los motivos por los cuales, cuando yo aún daba clase, solía decirles a los asistentes que quien a lo largo de su carrera no leía un texto de Koselleck no se dedicaba suficientemente a la historia en un sentido intelectual. Por eso me parece que la obra de Koselleck se incluye con toda razón entre los textos clave del siglo XX.

28. En su discurso de agradecimiento por el Premio Sigmund Freud, ante la Deutsche Akademie für Sprache und Literatur http://www.deutscheakademie.de/de/auszeichnungen/sigmund-freud-preis/reinhart-koselleck

29. Se trata de una conocida expresión (Das ist ein weites Feld), procedente de la novela Effie Briest (1895) de Theodor Fontane ("es un campo muy amplio y, además, la gente es muy diferente una de otra"), retomada por Günter Grass para una de sus novelas (1995), traducida al castellano como Es cuento largo (nota del traductor). 